\title{
Gastric secretory and plasma hormonal responses to sham-feeding of varying duration in patients with duodenal ulcer
}

\author{
S J KONTUREK,* J SWIERCZEK, N KWIECIEŃ, W OBTUTOWICZ, M DOBRZAŃSKA, \\ B KOPP, AND J OLEKSY
}

From the Institute of Physiology, Medicui Academy, Kraków, and District Hospital, Kraków, Poland

SUMMARY Gastric acid and serum gastrin, pancreatic polypeptide, and insulin responses to cephalic vagal stimulation were studied in eight patients with duodenal ulcer using modified shamfeeding for periods varying from four to 30 minutes. In addition, the maximal acid response to sham-feeding was compared with that induced by pentagastrin in 10 healthy subjects and 14 patients with duodenal ulcer. It was found that the gastric acid response to modified sham-feeding reached the maximal value after 15 minutes of sham-feeding and amounted to about $68 \%$ of the pentagastrin maximum. The serum pancreatic polypeptide response was also increased after modified sham-feeding and depended on the duration of this procedure, whereas gastrin and insulin responses were not significantly affected by modified sham-feeding. When the peak acid output induced by modified sham-feeding was normalised as percentage of the peak response to pentagastrin, it was similar in healthy subjects and in patients with duodenal ulcer; this indicates that the increased peak acid response to modified sham-feeding observed in patients with duodenal ulcer corresponded with their greater parietal cell mass rather than with increased vagal tone.

It is well established that the physiological vagal excitation accomplished by the 'chew and spit' technique results in a potent gastric secretory stimulation ${ }^{1-3}$ accompanied by a rise in plasma hormonal levels. ${ }^{3-7}$ The gastric acid secretory rate achieved by this modified sham feeding in duodenal ulcer patients was found to be of similar range to that attained by adequate sham-feeding, ${ }^{8}$ but no study was performed to determine the relationship between the duration of the modified sham-feeding and the gastric secretory response. In dogs, it has been shown that a marked gastric secretion occurred after less than one minute of sham-feeding and that when the duration of sham-feeding was extended there was a further increase in gastric secretion ${ }^{9}$ and proportional increments in plasma gastrin or insulin levels were observed. ${ }^{5}$ The maximal acid response to shamfeeding in these animals was not significantly different from that achieved by gastrin. ${ }^{9}$ No similar studies have been so far performed in man, although the modified sham-feeding has been widely used to study vagal control of gastric secretion.

*Address for correspondence: Professor Dr SJ Konturek, Institute of Physiology, 31-531 Kraków, ul. Grzegórzecka 16, Poland.

Received for publication 16 May 1981
This study was designed to determine the relationship between the duration of the modified sham-feeding and the gastric secretory and plasma hormonal responses to this procedure and to compare the maximal gastric acid response to modified sham-feeding and to pentagastrin in healthy subjects and duodenal ulcer patients.

\section{Methods}

\section{SUBJECTS}

Ten healthy male subjects (mean age 20 years, range 19-22 years; mean weight $71 \mathrm{~kg}$, range 66-77 g) and 20 male patients (age 20 years, range 19-23 years; mean weight $68 \mathrm{~kg}$, range $61-75 \mathrm{~kg}$ ) with wellestablished chronic duodenal ulcer disease in clinical remission were repeatedly examined. These subjects were divided by chance into two groups $\mathbf{A}$ and $\mathbf{B}$. Group A consisted of eight duodenal ulcer patients used in studies on the duration of the modified shamfeeding and group B included 10 healthy subjects and 14 patients with duodenal ulcer used to compare the maximal responses to modified sham-feeding and pentagastrin. The study was approved by a Human Research Review Committee and informed consent was obtained from each subject. 


\section{SECRETORY PROCEDURE}

The tests were performed after an overnight fast and any anticholinergic or antisecretory medication was withdrawn at least five days before the study.

A double lumen Dreiling tube was passed under fluoroscopic control for gastric juice collection as described previously. ${ }^{10}$ Residual gastric contents were discarded and the gastric aspirates were collected by a suction pump in 15 minute periods. The amount of acid collected was determined by titration to $\mathrm{pH} 7.0$ with $0.1 \mathrm{M} \mathrm{NaOH}$ using an automatic titrator (Autoburette Radiometer, Copenhagen). Pepsin activity in the gastric juice was measured by a modification of the Anson ${ }^{11}$ haemoglobin method and pepsin outputs were expressed in milligrams of pepsin per 15 minutes.

After a 60 minute basal period, the subjects were served an appetising meal consisting of $250 \mathrm{~g}$ beef steak, $150 \mathrm{~g}$ french potatoes, with about $250 \mathrm{ml}$ water to drink. The food was tested, chewed, and spat out. All meals were prepared in a separate building so that the subjects could not see or smell the food until the time for the sham-feeding and each subject was trained in a preliminary study not to swallow food during chewing. On different occasions, the modified sham-feeding procedure lasted $4,7.5,15$, or 30 minutes. Therefore, each subject was tested four times in order to compare the effects of shorter and longer duration of modified sham-feeding in the same individual. During all tests gastric aspirates were carefully checked for swallowed food particles and little or none was found. The gastric juice collections were made up to 120 minutes from the beginning of modified shamfeeding.

For the comparison, maximal acid output was determined in each subject using 90 minute intravenous infusion of pentagastrin $2 \mu \mathrm{g} / \mathrm{kg} / \mathrm{h}$, which was shown previously to elicit maximal secretory response to this peptide. The highest two consecutive 15 minute outputs were used to calculate the peak 30 minute maximal acid response to pentagastrin. The peak acid response to the modified sham-feeding was calculated from the highest two consecutive outputs and expressed as a percentage of the pentagastrin maximum. In addition, the total 120 minute acid outputs were calculated in each case to express the overall secretory response to modified sham-feeding either in $\mathrm{mmol} / 120 \mathrm{~min}$ or as a percentage of pentagastrin induced maximal acid output.

\section{RADIOIMMUNOASSAY}

Venous blood samples were obtained from a peripheral vein every 30 minutes, twice before the modified sham-feeding and at 15,30, 45, 60, 90 and 120 minutes thereafter. Serum gastrin, pancreatic polypeptide, and insulin were measured in each sample.

Gastrin iodination was carried out according to Walsh. ${ }^{12}$ After preliminary purification of the tracer through the G-10 column, monoiodinated gastrin was isolated by ion exchange chromatography on DEAE Sephadex A-25 by the method of Brown et al. ${ }^{13}$ Gastrin antiserum 4562 kindly donated by $\mathrm{Dr}$ J F Rehfeld of Aarhus, Denmark, was used at a final dilution 1:140000. With this antibody G-17 and G-34 were measured on nearly equimolar basis. Dextran-coated charcoal was used to separate labelled gastrin-bound antibody from free ${ }^{125} \mathrm{I}$-gastrin. Each sample was assayed in duplicate. The sensitivity of the gastrin measurement in the present assay was $5 \mathrm{pg}$ per $\mathrm{ml}$ serum equivalent to human heptadecapeptide gastrin.

In the assay of pancreatic polypeptide the freshly labelled human $\mathrm{PP}^{14}$ (HPP) was purified on the column of QAE Sephadex by the method of $J$ Ørgensen and Larssen. ${ }^{15}$ Antiserum against pancreatic polypeptide (a generous gift of $\mathrm{Dr} R$ A Chance, Eli Lilly Co., Indianopolis, Ind.) was used at a final dilution of $1: 1250000$. Highly purified HPP served as standard for all the assays. The assay tubes containing 1:10 diluted plasma and antiserum were incubated for 48 hours at $4^{\circ} \mathrm{C}$. Tracer was added and the incubation was then allowed to proceed for another 24 hours. Separation of antibody bound from free labelled HPP was performed by dextran coated charcoal. The experimental detection limit was $4 \mathrm{pmol} / \mathrm{l}$ plasma.

Insulin determinations were carried out by radioimmunoassay ${ }^{16}$ using anti-insulin guinea-pig serum at a final dilution of $1: 80000$.

\section{STATISTICS}

Results are expressed as mean \pm SEM. Statistical significance was determined by both the Wilcoxon signed rank test and the paired $t$ test. Significance was accepted with $P$ values less than 0.05 .

Integrated pancreatic polypeptide response IPPR was calculated according to the following formula:

$$
\begin{aligned}
& \text { IPPR }=\frac{P P_{0}+P P_{1}}{2} t_{1}-t_{0}+ \\
& \ldots \ldots \frac{P P_{n+1} P P_{n}}{2} t_{n}-t_{n-1}
\end{aligned}
$$

Thus, IPPR was calculated by trapez-integration from zero to the 60 minute sample with the mean basal pancreatic polypeptide concentration subtracted. 


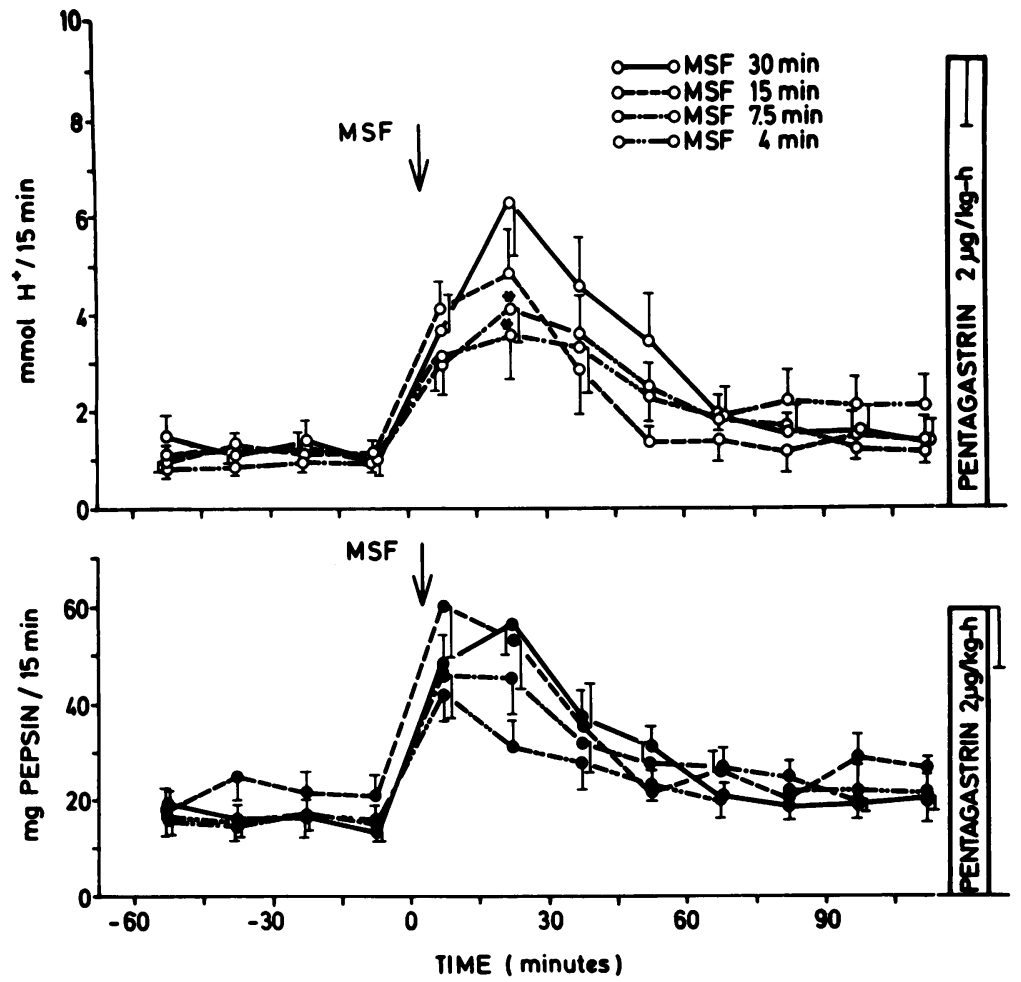

Fig. 1 Time-course of the mean \pm SEM acid and pepsin secretion in eight patients with duodenal ulcer in response to modified sham-feeding varying from four to 30 minutes.

Results

The time-course of gastric and pepsin secretion in response to modified sham-feeding of varying duration in eight patients with duodenal ulcer is shown in Fig. 1. The mean acid output reached its peak in the second 15 minute period after the start of the modified sham-feeding and was significantly raised above basal level for about one hour after that. The mean 15 minute peak acid response to the modified sham-feeding of $4,7 \cdot 5,15$, and 30 minutes duration amounted to $40,50,53$, and $68 \%$ of the mean pentagastrin maximum, respectively. The difference in the 15 minute peak response to modified sham-feeding of 4 or 7.5 minutes duration and that of 30 minutes duration was statistically significant. No significant difference was found in the 15 minute peak outputs between 4 and 7.5 minutes or between 15 and 30 minutes' duration of modified shamfeeding.

In most of the tests two highest consecutive acid outputs, 30 minute peak output occurred in the second and third 15 minute periods after the start of the modified sham-feeding but in some tests, particularly with modified sham-feeding of shorter duration, this 30 minute peak output appeared in the first and second 15 minute periods. The peak output

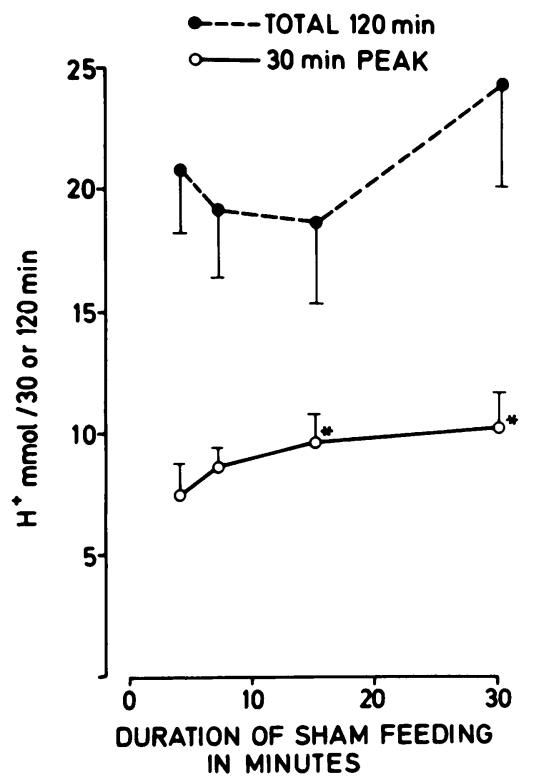

Fig. 2 Peak 30 minute and total 120 minute acid responses to modified sham-feeding plotted against its duration. On this and a subsequent Figure an asterisk indicates a significant, $\mathrm{P} 0 \cdot 05$, increase above secretory responses to 4 minute modified sham-feeding. 
tended to be higher when the time-course of modified sham-feeding was prolonged. Nevertheless, only at 15 and 30 minute feeding was it significantly higher than that at four minute feeding. The overall 120 minute acid responses did not show, however, significant differences when plotted against the duration of modified sham-feeding (Fig. 2). Similar results were obtained with the acid responses expressed as percentages of pentagastrin maximum either for the 30 minute peak or the total 120 minute acid secretion (Fig. 3).

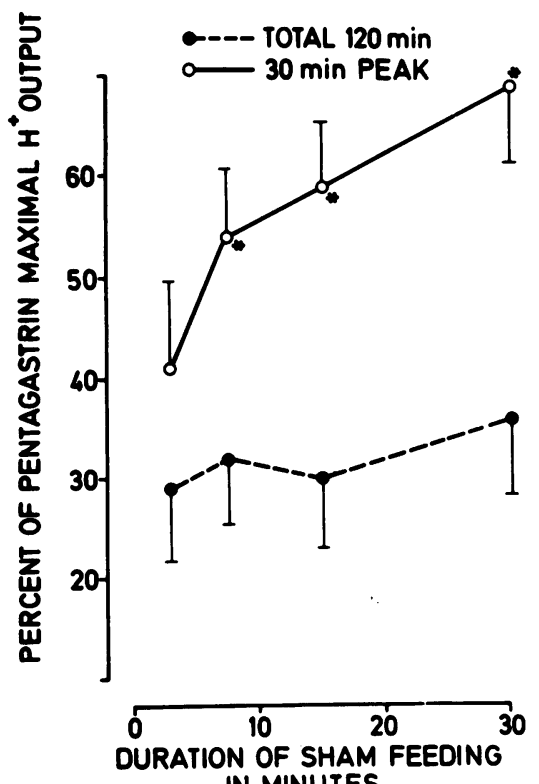

IN MINUTES

Fig. 3 Peak 30 minute and total 120 minute acid responses as percentages of pentagastrin maximum plotted against duration of modified sham-feeding.
The mean peak pepsin outputs in response to modified sham-feeding occurred in most tests during the first 15 minute period after the start of the procedure and it was not statistically different from that obtained with pentagastrin. The changes in pepsin outputs in response to modified sham-feeding corresponded with the alterations in the volume flow of gastric juice without significant change in pepsin concentrations. The difference in the peak pepsin outputs recorded in tests with modified sham-feeding of different duration was not statistically significant (Fig. 1).

As shown in the Table, modified sham-feeding led to a rapid increase in serum pancreatic polypeptide concentration, reaching the peak usually in the first 15 minute period after the start of modified shamfeeding. There was, however, a marked variation in the pancreatic polypeptide response from subject to subject, and some subjects showed little or no response, particularly in tests with shorter duration of modified sham-feeding (Fig. 4). The mean one hour integrated pancreatic polypeptide response was negligible after the modified sham-feeding of 4 and 7.5 minutes' duration but showed significant increase after the feeding of 15 or 30 minutes' duration (Fig. 5). The effects of modified sham-feeding on serum gastrin and insulin levels are presented in the Table. No significant change in serum gastrin or insulin was noted during or after the modified sham-feeding, although there was some tendency of the serum gastrin or insulin to increase immediately after the start of the feeding.

In another group, group B, of 10 healthy subjects and 14 patients with duodenal ulcer, the 30 minute peak acid response to the feeding tended to achieve higher value in patients with duodenal ulcer than in normal subjects but the difference was not significant

Table Plasma hormonal responses to modified sham-feeding of varying duration in duodenal ulcer patients

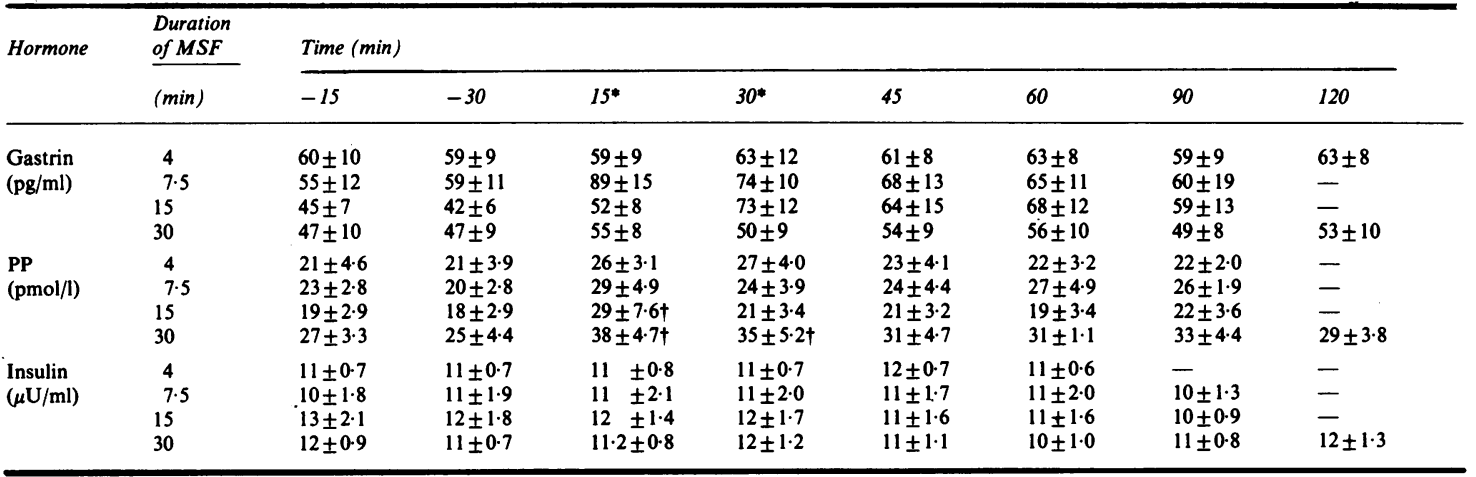

* Periods when modified sham-feeding was performed.

$\dagger$ Significantly different from basal $\mathrm{P}<0.05$.

- Not tested. 


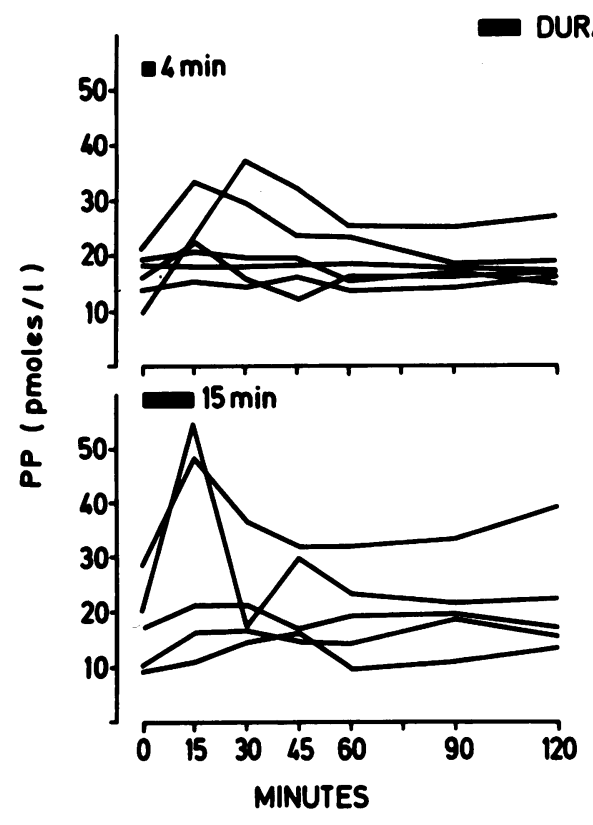

DURATION OF MSF

$7.5 \mathrm{~min}$
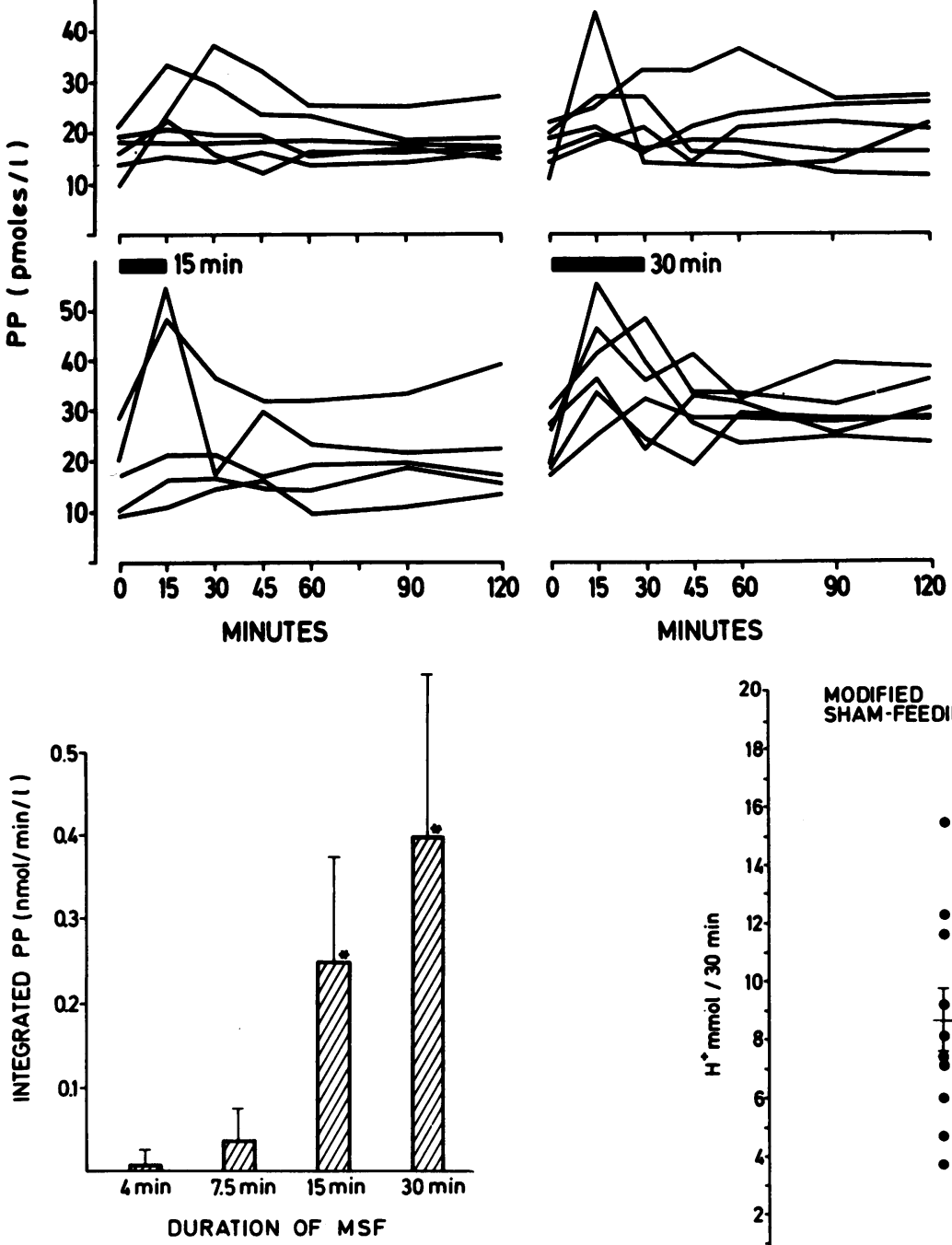

Fig. 4 Individual plasma pancreatic polypeptide concentrations induced by modified sham-feeding of varying duration in

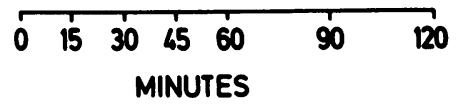
patients with duodenal ulcer.

Fig. 5 Mean integrated pancreatic polypeptide response to modified sham-feeding of 4, 7.5, 15 and 30 minutes' duration in patients with duodenal ulcer.

(Fig. 6). The modified sham-feeding response expressed as a percentage of pentagastrin maximum was similar in healthy subjects-63\% -and in patients with duodenal ulcer-62\%. There was a close correlation between the peak acid response to the feeding and to pentagastrin, both in normal subjects $(Y=0.929 \times+5.5, r=0.906)$ and in duodenal ulcer patients $(\mathrm{Y}=1.11 \times+6.15, \mathrm{r}=0.806)$ (Fig. 7). No significant difference was found between the correlation lines of normal subjects and duodenal ulcer patients.

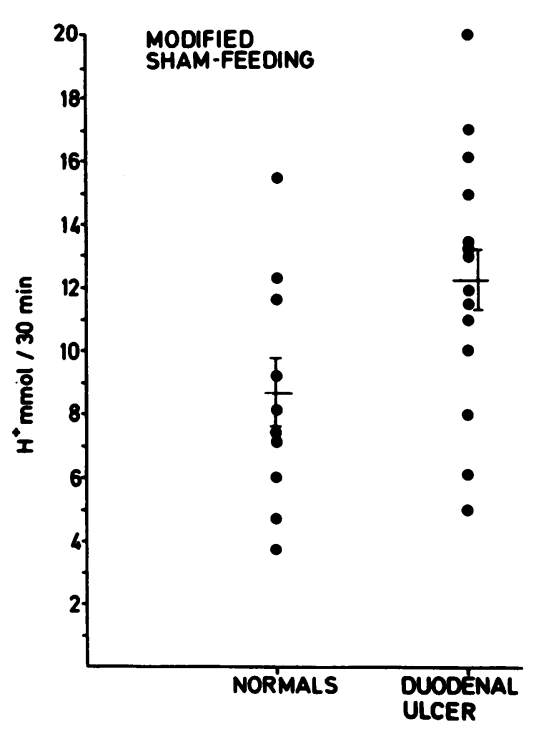

Fig. 6 Thirty minute peak acid responses to modified shamfeeding in 10 normal subjects and 14 patients with duodenal ulcer.

\section{Discussion}

This study provides evidence that the gastric acid response to cephalic phase stimulation depends upon the duration of the modified sham-feeding and that it reached about $68 \%$ of the maximal response to pentagastrin. The maximal response to the feeding was obtained after 15 minutes as doubling the duration 


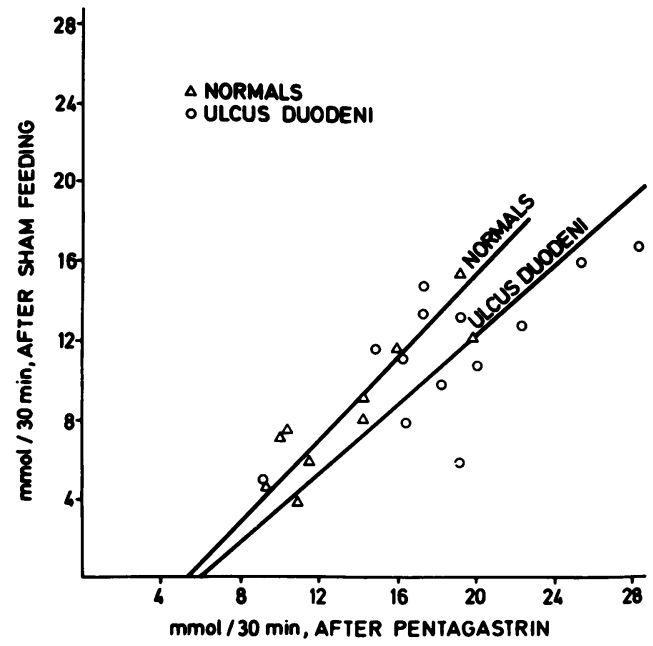

Fig. 7 Correlation between the 30 minute peak acid outputs in response to the modified sham-feeding and pentagastrin in normal subjects and patients with duodenal ulcer (normal subjects: $Y=0.929 \times+5 \cdot 5, r=0.906$; patients with duodenal ulcer: $Y=1 \cdot 11 \times+6 \cdot 15, r=0.806)$.

of the procedure did not cause any further significant rise in acid output. Although 4 and 7.5 minute modified sham-feeding produced significantly lower acid response than that of 15 or 30 minutes' duration, the difference was not very impressive. If expressed in terms of the percentage of pentagastrin maximum, 4 minute modified sham-feeding induced only about $27 \%$ smaller response than that of 30 minute feeding.

In contrast with acid output, pepsin response to modified sham-feeding of shorter duration, 4 or 7.5 minutes, was not significantly different from that achieved with feeding of longer duration, 15 or 30 minutes. This was probably due to the marked individual variation in pepsin secretion in response to modified sham-feeding and to the rather small number of subjects tested.

In contrast with dogs, which were shown to respond to the sham-feeding with an increase in acid output of similar magnitude to that achieved with maximal gastrin stimulation, ${ }^{9}$ sham-feeding in healthy subjects and patients with duodenal ulcer produced response amounting to about 63 and $62 \%$ of pentagastrin maximum, respectively. The reason for the relatively lower acid response to sham-feeding than to gastrin in man is not obvious but it may be due to the activation of the inhibitory mechanism during physiological vagal stimulation. The nature of this mechanism is unknown but it is worthwhile to mention that the stimulation of vagal centres by insulin hypoglycaemia also produced significantly smaller acid response than that achieved by betazole or pentagastrin. In addition, graded doses of insulin resulted in graded acid outputs, indicating that the response to insulin, like that to modified shamfeeding, is not an all-or-none phenomenon.

As modified sham-feeding involves excitation of the vagal nerves, which, it has been suggested, exhibit higher 'tone' in patients with duodenal ulcer, ${ }^{19}$ it was expected that these patients would secrete more acid in response to the cephalic phase stimulation than healthy subjects. Such an increase in vagal 'capacity' as measured by the ratio of insulin- to pentagastrininduced acid secretion was reported in duodenal ulcer patients. ${ }^{20} 21$ Our study shows that the mean peak acid response to the modified sham-feeding was only slightly higher in patients with duodenal ulcer but this does not seem to reflect any more vigorous secretory reaction of their stomachs to vagal excitation; rather, it probably corresponds to a greater size of the parietal cell mass. This is evidenced by the higher rates of pentagastrin-induced maximal acid secretion and very close positive correlation between the peak acid responses to modified sham-feeding and to pentagastrin.

It is of interest that, in spite of the abundant gastric acid and pepsin secretion, no significant changes in serum gastrin or insulin levels were observed. This disagrees with the recent report of Feldman and $\mathrm{Walsh}^{3}$ who found a significant rise in serum gastrin level during modified sham-feeding in tests both with simple aspiration of the gastric juice or maintaining the gastric content at $\mathrm{pH} 5 \cdot 0$. Stenquist et al. ${ }^{22}$ reported, however, that adequate and modified sham-feeding in duodenal ulcer patients caused the usual increase in acid secretion to a peak of about $50 \%$ of pentagastrin maximum, but failed to raise significantly either total gastrin or G17 concentration in the plasma. Our previous reports with the cephalic phase stimulation in healthy subjects or duodenal ulcer patients also failed to reveal any significant alteration in serum gastrin during or after the modified sham-feeding. ${ }^{2} 2324$ The reason for the discrepancy in the results of gastrin response to cephalic phase stimulation so far reported is not known, but it should be emphasised that the increase in gastrin response to sham-feeding reported by Feldman and Walsh ${ }^{3}$ was rather small in comparison with that observed in sham-fed dogs. ${ }^{25}$ This suggests a major quantitative difference in the cephalic phase stimulation between these two species-namely, that in humans it is mediated mainly by the direct cholinergic excitation of the parietal cells whereas, in dogs, it is largely mediated by vagal release of gastrin.

In contrast with gastrin, the serum PP-response to the MSF was clearly increased and related closely to the duration of cephalic phase stimulation. Actually 
an increase in serum pancreatic polypeptide response was significant only after 15 and 30 minutes but not after 4 or 7.5 minutes' modified sham-feeding. With increasing duration of the sham-feeding the pancreatic polypeptide response was higher, longer, and less variable. These results remain in good agreement with previous reports showing that the cephalic phase provoked by tasting, chewing, or swallowing resulted in a rapid pancreatic polypeptide response, probably mediated by a vagal mechanism because it could be eliminated by truncal vagotomy ${ }^{6} \quad 25-27$. Our study provides the first evidence that the polypeptide response to the modified sham-feeding is related to the duration of the cephalic phase.

Unlike pancreatic polypeptide, serum insulin did not show any significant change during or after sham-feeding. This remains apparently discrepant with the finding in dogs in which simple teasing caused a moderate rise in plasma insulin, ${ }^{5}$ whereas sham-feeding produced a marked increase in plasma insulin level which was related to the duration of the sham-feeding. The insulin response in these experiments occurred almost immediately after the start of the sham-feeding and then fell dramatically towards the baseline before the end of this procedure. As we collected the blood samples at only 15 minute intervals, it is likely that this peak insulin response could be simply overlooked. Thus, the negative data do not appear to rule out insulin secretion in response to modified sham-feeding.

\section{References}

${ }^{1}$ Richardson CT, Walsh JH, Cooper KA, Feldman M, Fordtran JS. Studies on the role of cephalic-vagal stimulation in the acid secretory response to eating in normal human subjects. J Clin Invest 1977; 60:435-41.

${ }^{2}$ Konturek SJ, Kwiecień N, Obtutowicz W, Mikoś E, Sito E, Oleksy J, Popiela T. Cephalic phase of gastric secretion in healthy subjects and duodenal ulcer patients: role of vagal innervation. Gut 1978, 20:875-81.

${ }^{3}$ Feldman M, Walsh JH. Acid inhibition of sham feedingstimulated gastrin release and gastric acid secretion: Effect of atropine. Gastroenterology 1980; 78:772-6.

${ }^{4}$ Knutson U, Olbe L, Ganguli PC. Gastric acid and plasma gastrin responses to sham-feeding in duodenal ulcer patients before and after resection of antrum and duodenal bulb. Scand J Gastroenterol 1974; 9:351-6.

${ }^{5}$ Nilsson G, Uvnäs-Wallensten $\mathbf{K}$. Effect of teasing, sham feeding and feeding on plasma insulin concentrations in dogs. In: Becker W, ed. Diabetes mellitus. Stuttgart: Thieme Verlag, 1977: 91-7.

${ }^{6}$ Taylor IL, Feldman M, Richardson CT, Walsh JH. Gastric and cephalic stimulation of human pancreatic polypeptide release. Gastroenterology 1978; 75:432-7.

${ }^{7}$ Schwartz TW, Stenquist B, Olbe L. Cephalic phase of pancreatic-polypeptide secretion studied by sham feeding in man. Scand J Gastroenterol 1979; 14: 313-20.

${ }^{8}$ Stenquist B, Knutson U, Olbe L. Gastric acid responses to sham-feeding and modified sham feeding in duodenal ulcer patients. Scand J Gastroenterol 1976; 11, suppl 37, 41.

${ }^{9}$ Preshaw RM. Gastric acid output after sham feeding and during release or infusion of gastrin. Am J Physiol 1970; 219:1409-16.

${ }^{10}$ Konturek SJ, Biernat J, Kwiecień N, Oleksy J. Effect of glucagon on meal-induced gastric secretion in man. Gastroenterology 1975; 68:448-54.

${ }^{11}$ Anson ML. The estimation of pepsin, trypsin, papain and cathepsin with hemoglobin. J Gen Physiol 1938; 22:78-79.

12 Walsh JH. Radioimmunoassay of gastrin. In: Rothfield B, ed. Nuclear medicine in vitro. Philadelphia, Lippincott 1979: 231-48.

${ }^{13}$ Brown TR, Bagcki N, Mack RE, Booth E, Jones DP. Isolation of monoiodinated gastrin using DEAESephadex and its characteristics in the gastrin radioimmunoassay. Clin Chim Acta 1976; 67:321-3.

${ }^{14}$ Taylor IL, Impicciatore M, Carter DC, Walsh JH. Effect of atropine and vagotomy on the pancreatic polypeptide response to a meal in dogs. Am J Physiol 1978; 235: E443-7.

15 Jorgensen KH, Larsen UD, Purification of $125 \mathrm{~J}$-glucagon by anion exchange chromatography. Horm Metab Res $1972 ; 4: 223-224$.

${ }^{16}$ Herbert V, Lau KS, Gottlieb CW, Bleicher SJ. Coated charcoal immunoassay of insulin. $J$ Clin Endocrinol Metab 1965; 25:1375-84.

${ }^{17}$ Faroog O, Isenberg JI. Effect of continuous intravenous infusion of insulin versus rapid intravenous injection of insulin on gastric acid secretion in man. Gastroenterology 1975; 68:683-686.

${ }^{18}$ Baron JH, Cowley DJ, Guttierrez LV, Iweze FI, Spencer $\mathbf{J}$, Tinker $\mathbf{J}$. Dose response of gastric acid to insulin in patients with duodenal ulcer. Gastroenterology 1972; 62:203-6.

${ }^{19}$ Dragstedt LR. A concept of aetiology of gastric and duodenal ulcer. Gastroenterology 1956; 30:208.

${ }^{20}$ Lam SK, Sircus W. Vagal hyperactivity in duodenal ulcer: with and without excessive acid secretion. Rendic Gastroenterol 1975; 7:5-9.

${ }^{21}$ Lam SK, Sircus W. A comparison of the acid and gastrin secretory responses to hypoglycemia and meals in duodenal ulcer with and without acid hypersecretion to pentagastrin. Digestion 1976; 14:1-11.

22 Stenquist B, Nilsson G, Rehfeld JF, Olbe L. Plasma gastrin concentrations following sham feeding in duodenal ulcer patients.Scand J Gastroenterol 1979; 14:305-11.

${ }^{23}$ Konturek SJ, Obtutowicz W, Kwiecień N, Sito E, Mikoś $\mathrm{E}$, Oleksy J. Comparison of ranitidine and cimetidine in the inhibition of histamine, sham-feeding, and mealinduced gastric secretion in duodenal ulcer patients. Gut 1980; 21 :181-6.

${ }^{24}$ Konturek SJ, Obtutowicz W, Kwiecień N, Dobrzańska M, Swierczek J, Kopp B, Oleksy J. Effect of pirenzepine and atropine on gastric secretory and plasma hormonal responses to sham feeding in patients with duodenal ulcer. Scand J Gastroenterol (Suppl 66) 1980; 15:63-9. 
25 Tepperman BL, Walsh JH, Preshaw RM. Effect of antral denervation on gastrin release by sham feeding and insulin hypoglycemia in dogs. Gastroenterology 1972; 63: 973-980.

${ }^{26}$ Schwartz TW, Stadil F, Chance RE, Rehfeld JF, Larsson LI, Moon N. Pancreatic polypeptide response to food in duodenal ulcer patients before and after vagotomy. Lancet 1976; 1:1102-5.

${ }^{27}$ Stern AI, Hansky J, Korman MG, Coupland GC, Waugh J. Pancreatic polypeptide. Release following surgery for duodenal ulcer disease. Dig Dis Sci 1980; 25: 485-8. 